\title{
Acessibilidade, Gênero e EducaÇão Superior: Indicativos Procedentes DAS INVESTIGaÇÓES Científicas ${ }^{1}$ \\ ACCESSIBILITY, GENDER AND HighER EDUCATION: INDICATORS FROM SCIENTIFIC RESEARCH
}

\author{
Jackeline Susann Souza da SILVA² \\ Francisca GONZÁLEZ-GIL ${ }^{3}$
}

\begin{abstract}
RESUMO: o presente artigo objetiva apresentar uma revisão de literatura da produção que articula acessibilidade, gênero e educação superior, publicada de 2013 ao período atual. Para situar o objeto de estudo dentro da ampla divulgaçáo de trabalhos científicos, os pesquisadores necessitam eleger um método que contemple informaçốes pertinentes e respalde o problema de pesquisa. Essa fase da investigação, portanto, envolve a escolha de critérios para a gestão de buscas e de procedimentos para comparação, tipificação e análise das publicaçôes entre si e com a pesquisa que se pretende desenvolver. Nesse contexto, é propósito deste texto divulgar uma alternativa de desenho de revisão feita a partir da categorização e análise realizadas por meio do Programa NVivo 11 e da leitura pormenorizada de 72 pesquisas desenvolvidas em Brasil, Espanha, Colômbia, Chile, México e Canadá. Com o software de busca, a identificação das palavras mais frequentes permitiu a elaboração de um mosaico conceitual que guiou a discussão da pesquisa em questáo. Já as palavras ausentes e que são importantes para o desenvolvimento da tese - como gênero, feminismo e mulher - revelam a emergência de introduzir estes termos em um trabalho investigativo. $\mathrm{O}$ resultado desta revisão de literatura mostra que o estudo sobre acessibilidade na educaçấo superior é desenvolvido em predominância por mulheres e que a multidimensionalidade do sentido da acessibilidade faz com que os pesquisadores busquem respostas em outros campos, saindo assim, dos limites da hiperespecialização da Educação Especial. Esse aspecto pode contribuir para a inovação e avanço do conhecimento em foco.
\end{abstract}

PALAVRAS-CHAVE: Educação Especial. Revisão de Literatura. Educação Superior.

\begin{abstract}
This article aims to present a literature review of texts that articulate accessibility, gender and higher education published from 2013 to the current period. To place the object of study within the wide dissemination of scientific works, researchers must choose a method that includes information relevant to the research problem. This phase of the investigation, therefore, involves the choice of criteria for search management and procedures for comparing, categorizing and analyzing publications among themselves and with the research to be developed. In this context, the purpose of this text is to disseminate an alternative to literature review design made from the categorization and analysis carried out through NVivo 11 Program and the detailed reading of 72 papers developed in Brazil, Spain, Colombia, Chile, Mexico and Canada. With the search software, the identification of the most frequent words allowed the elaboration of a conceptual mosaic that guided a discussion of the present research. However, the words lacking in the search procedure, but important for the development of the thesis - such as gender, feminism and woman - reveal the need to introduce these terms into an investigative work. The result of this literature review shows that the study on accessibility in higher education is developed predominantly by women and that the multidimensionality of the meaning of accessibility causes researchers to seek answers in other fields of knowledge, thus escaping the limits of the hyperspecialization of Special Education. This aspect can contribute to innovation and advancement of knowledge in focus.
\end{abstract}

KEYWORDS: Special Education. Literature Review. Higher Education.

\section{INTRODUÇÁO}

Esta revisão de literatura é parte de uma investigação de doutorado (em andamento) que tem como objetivo caracterizar as condiçóes de acessibilidade para mulheres com deficiên-

\footnotetext{
${ }^{1}$ http://dx.doi.org/10.1590/S1413-65382317000400010

${ }^{2}$ Doutoranda em Educação pela Universidad de Salamanca. Membro do Grupo de Estudo e Pesquisa CNPq Vozes, Empoderamento, Inclusão e Direitos Humanos. João Pessoa, PB, Brasil. jackelinesusann@usal.es

${ }^{3}$ Professora Titular en el Departamento de Didáctica, Organización y Métodos de Investigación. Faculdade de Educação, Universidad de Salamanca. Grupo de Investigación en Educación Inclusiva. Salamanca, Espanha. frang@usal.es
} 
cia que estão na educação superior. As mulheres com deficiência fazem parte de um grupo que sofre risco social por causa da combinação da marca de gênero e deficiência, por isso elas encontram barreiras em âmbito educacional, social e econômico e, em decorrência, limitadas chances de desenvolvimento humano se comparado a outros grupos (DANTAS; SILVA; CARVALHO, 2014). Nos debates contemporâneos sobre as pessoas com deficiência, as mulheres com deficiência ainda são raramente mencionadas como um grupo específico, provavelmente porque ao aludir 'pessoa com deficiência' ou 'mulheres' supóe-se que, implicitamente, se incluem as demandas de mulheres com deficiência no discurso. No entanto, essas mulheres trazem consigo condições de vida particulares que não são vivenciadas por homens com deficiência, nem tampouco por mulheres sem deficiência.

Trazendo este tópico para o contexto da educação superior, é consensual a convicção sobre a relevância desse nível educacional para a regulamentação da vida em geral e seu potencial empoderador, crítico e avaliador das problemáticas sociais. Porém, o crédito de 'coletivo pensante' é restrito a um grupo seleto, uma vez que a universidade tradicionalmente se constituiu em um espaço de privilégio e poder alcançado pela minoria da população brasileira sem deficiência. Nesse quadro, menos de $0,8 \%$ de estudantes com deficiência que estão na educação básica consegue ascender ao nível de formação superior no país (BRASIL, 2015).

Vale destacar que se tratando de gênero, acessibilidade e educação superior esta temática ainda é inexplorado na literatura, escondendo as barreiras e a opressão de gênero que estão por trás das inacessibilidades. Por isso, é necessário um trabalho de revisão de literatura que confirme (ou não) a ausência de estudos e, ao mesmo tempo, oportunize a imersão da pesquisa na discussão atualizada sobre acessibilidade na educação superior. Esta fase de revisão de literatura se caracteriza como o ponto de partida da investigação e o momento em que se indicam "os procedentes sobre o tema investigado" (BRAVO, 1996, p. 34), ou seja, as lacunas e os avanços que situam o problema, mostrando os caminhos que podem ser explorados na metodologia.

Vale salientar que, antes de realizar a revisão de literatura, as asseveraçóes sobre o problema são incipientes e na fase de contraste com as informaçóes que existem podem ser refutadas, ampliadas e aprofundadas. Desta forma, a revisão de literatura é um momento significativo para a pesquisa porque fundamenta a relevância e a justificativa do problema de pesquisa, alicerçando as razóes pelas quais um tema necessita ser investigado e as contribuições científicas e sociais que a pesquisa aportará para o estado da arte atual.

\section{Método}

O levantamento dos textos foi realizado nos repositórios on-line de artigos e de pesquisas de mestrado e doutorado da Universidade de Salamanca (USAL) ${ }^{4}$ e da Comissão de Aperfeiçoamento de Pessoal do Nível Superior (CAPES) ${ }^{5}$. As investigaçóes selecionadas incluem trabalhos escritos em língua Espanhola, Portuguesa e Inglesa, publicados no período de janeiro de 2013 até fevereiro de 2017. Para a delimitação deste período foi levado em conside-

\footnotetext{
${ }^{4}$ Disponível em: http://gredos.usal.es/jspui/

${ }^{5}$ Disponível em: http://bancodeteses.capes.gov.br/banco-teses/
} 
ração a continuidade de uma revisão de literatura anterior, realizada entre os anos 2000-2012 em que o tema da acessibilidade na educação superior era praticamente inexplorado pelos pesquisadores brasileiros. No entanto, com a atualização da revisão ficou perceptível que nos últimos seis anos, começou a disseminar-se um grande número de publicaçôes com o foco na acessibilidade para pessoas com deficiência nos cursos superiores, que envolvem a análise da acessibilidade em um contexto variado como a investigação de ambientes, metodologias de ensino, sistema de comunicacional e informação, atitudes e serviços institucionais.

Para a identificação dos textos nos bancos de dados foram utilizadas os descritores 'acessibilidade', 'deficiência', 'gênero' e 'educação superior/universidade', com variaçôes de busca a partir do uso das palavras 'mulheres com deficiência', 'inclusão', 'tecnologia' e 'desenvolvimento'. A escolha das palavras-chave foi feita mediante a leitura dos eixos principais que compóem o argumento-chave desta tese, com objetivo de revisar os pressupostos construídos no projeto da pesquisa e os conceitos que serão trabalhados posteriormente.

A revisão da literatura ocorreu em seis etapas, conforme indica o fluxograma a seguir:

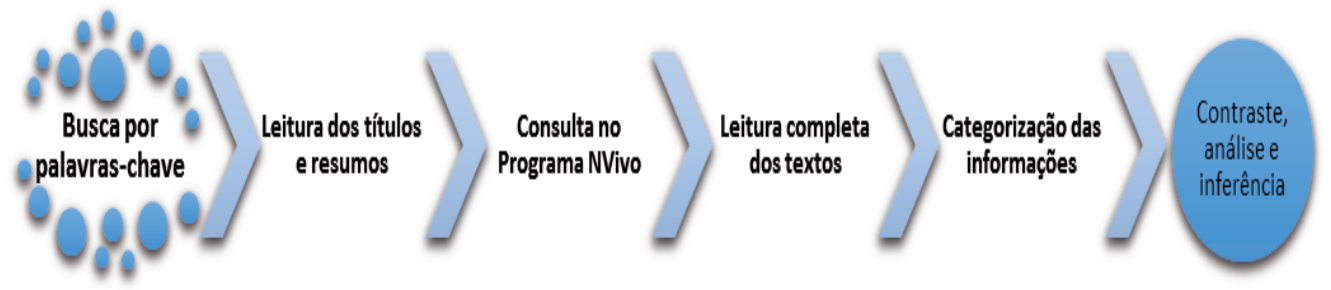

Figura 1 - Fluxograma do método de revisão de literatura.

Fonte: elaboração Própria

Primeiro foi feita a escolha das palavras chaves e dos bancos de dados para consulta. Logo após, foi realizada a leitura on-line dos títulos e resumos e, com base nessas informações, elegemos os 72 textos dos 165 identificados, sendo 22 artigos completos, 40 dissertaçóes de mestrado e 10 teses cujo os objetos de estudos se aproximam da problemática que conduz esta pesquisa. A terceira etapa se consistiu na organização dos textos com código específico e na consulta deste material no Programa NVivo 11. Neste programa foram utilizados os recursos de consulta de frequência de palavras, árvore de conceitos e nuvem de palavras. Com o uso do NVivo caracterizamos e agrupamos de maneira global os temas mais explorados pelos pesquisadores. Já a quarta etapa, na fase de leitura completa, aprofundamos esses temas e identificamos novas e inexploradas questóes com atenção aos seguintes aspectos: (a) objetivos, perguntas orientadoras (se for o caso) e argumento central; (b) método e desenho da pesquisa; (c) principais conceitos e termos utilizados pelos investigadores e (d) conclusóes gerais. Os resultados dos dados obtidos por meio do Programa NVivo 11 e da leitura completa dos textos conduziram a quinta e a sexta etapas do método de revisão, nas quais foram categorizadas as informaçóes, contrastadas entre si e com o problema de tese (aqui levantado) e interpretadas à luz de nossas inferências e do quadro teórico adotado ao longo deste estudo.

${ }^{6}$ Esta primeira revisão de literatura sobre o tema foi realizada em uma pesquisa de mestrado realizada no Brasil e publicada em 2014. 


\section{Resultados E discussão}

\subsection{Panorama Das Pesquisas ReVISADas}

Por causa da escolha do banco de dados da CAPES e da USAL, maior parte das investigaçóes identificadas se concentra na Espanha (20,8\%) e no Brasil (68\%). No entanto, quatro países apareceram nas buscas: Colômbia $(7,4 \%)$, Chile $(2,9 \%)$, México $(1,4 \%)$ e Canadá $(1,4 \%)$. Esse intercâmbio na seleção de informação científica é condizente com a nova "ordem cosmopolita do saber" (CARUSO; TERORTH, 2011, p. 21) ou com o que Morin (2010, p. 10) chama de "migração de ideias", no qual a internacionalização do conhecimento se constrói na estratégia de redes de inter-relaçôes, que frente ao mundo digital, estâo contribuindo para diminuição das fronteiras geográficas, materiais, linguistas e simbólicas que distanciam produçóes, recepçóes e difusóes de textos científicos. Desta forma, a análise acerca da pesquisa de autores de diferentes localidades contribui para entender o significado diverso do conceito e da aplicabilidade da acessibilidade no âmbito universitário - desde os perfis de diferentes instituiçóes de educação superior e do marco político e legal dos países mencionados. Mais que valer-se de métodos comparativos que colocam em oposição realidades distintas, esta revisão de literatura busca, a partir das fontes variadas, construir um mosaico que ajude identificar categorias analíticas, aprofundar e inovar conceitos, normas e metodologias sobre o tema investigado.

No que se refere a área de conhecimento, constatou-se que o tema da acessibilidade transitou de maneira interdisciplinar. Em outras palavras, ainda que cada qual em seu campo de investigaçáo, os pesquisadores analisaram a acessibilidade a partir do aporte conceitual de distintas disciplinas, supostamente em razão da amplitude do sentido empírico da acessibilidade e da interdisciplinaridade intrínseca a este conceito. Assim, os textos mapeados nesta revisão de literatura se concentraram no grande campo da Educação e em subáreas como Educação Especial e Educação Agrícola. Também foram desenvolvidas pesquisas em linhas vinculadas à Psicologia, à Política e Gestáo, à Matemática, ao Design, à Arquitetura, à Engenharia, ao Direito, à Economia e à Cultura e Artes. A circulaçáo do conceito de acessibilidade em diferentes disciplinas e o hibridismo que resulta desta teorizaçáo são vantajosos porque escapam da especialização unilateral ou da "hiperespecialização do conhecimento" (MORIN, 2010, p. 10), que por tradição, provocou a segregaçáo e o isolamento da Educaçáo Especial dos outros campos científicos (SILVA; FERREIRA, 2017). Pode-se dizer que a investigação sobre acessibilidade é a que tem se aproximado do modelo social da deficiência porque olha para o cenário e as relaçóes fora da condição de deficiência e não para uma suposta tragédia pessoal (OLIVER, 1983), daí a necessidade de diminuir as fronteiras disciplinarias e encontrar respostas fora (MORIN, 2010) do que foi convencionado na Educação Especial.

A maioria das pesquisas se caracteriza como estudo qualitativo, no qual os dados foram coletados a partir do uso de entrevista, observaçáo, estudo documental e grupo focal (VILLA; ALLER; GARCÍA, 2014; MOOLA, 2015; RICARDO; ANGARIDA, 2014; BORGES, 2013; SILVA, 2014). Alguns pesquisadores mesclaram métodos qualitativos com técnicas de quantificação no uso de questionários e protocolos de acessibilidade (VIEJO; MARTÍNEZ, 2016; BAU, 2015). De forma geral, as pesquisas são desenvolvidas a partir de estudos exploratórios e descritivos (PÉREZ; AGUILAR, 2015; JUVENCIO, 2013; STROPARO, 2014; BRUNELLI, 2015; VIGENTIM, 2014). 
Muitos investigadores partiram de hipótese negativas, ou seja, seu recorte analítico foi construído a partir de pressupostos sobre necessidades, dificuldades, fracassos e barreiras presentes na trajetória de estudantes com deficiência na educação superior (VILLA; ALLER; GARCÍA, 2014; SALLÁN; MORENO, 2013; PÉREZ; AGUILAR, 2015). No entanto, alguns autores com base em resultados negativos propuseram recomendaçóes para mudanças e melhoria das condiçóes de acessibilidade na educação superior (LORENSI, 2014; SILVA, 2014; JUVENCIO, 2013; TAVARES, 2014; RIO; PASTOR, 2013).

Nesta revisão de literatura tivemos uma amostra de dados relacionados ao sexo dos pesquisadores. Dos 72 textos, o número total de investigadores foi de 88 - considerando que na modalidade artigo científico participaram mais de um autor. Deste total, 70,7\% são mulheres e 29,2\% homens. Este número induz a predominância de participação feminina no estudo sobre a temática em questão. É interessante destacar que a participação masculina, identificada nesta revisão de literatura, concentra os estudos sobre acessibilidade em disciplina exatas, por exemplo, a acessibilidade relacionada ao desenho universal e arquitetura, às tecnologias e comunicação assistiva e aos recursos e ambientes virtuais (SANTOS, 2014; BORGES, 2013; SERRA JUNIOR, 2014; FUENTES; VILLORIA; ALMARAZ, 2016; VIGENTIM, 2014). Esse dado está em consonância com os estudos de gênero que revelam que as mulheres tendem a se 'interessar' por áreas ligadas à função de cuidado e com caráter subjetivo, relacional e assistencial (PINTO; CARVALHO; RABAY, 2017), sendo sub-representadas nas ciências exatas e tecnológicas, diferentemente dos homens têm grande representação nestas áreas (BURIN, 2008; CRUZ, 2012). Pressupóe-se que por isso as pesquisas sobre deficiência são produzidas hegemonicamente por mulheres, justamente porque as pessoas com deficiência são um grupo vulnerável que, muitas vezes, se mantém sob a tutela e o cuidado das mulheres e também porque a deficiência é uma característica tomada predominantemente como objeto de estudo pela Psicologia, Educação e Assistência Social.

Com relação aos eixos temáticos, os principais temas desenvolvidos nas 72 investigaçóes podem ser divididos em seis grupos, conforme distribuídos no gráfico 1:

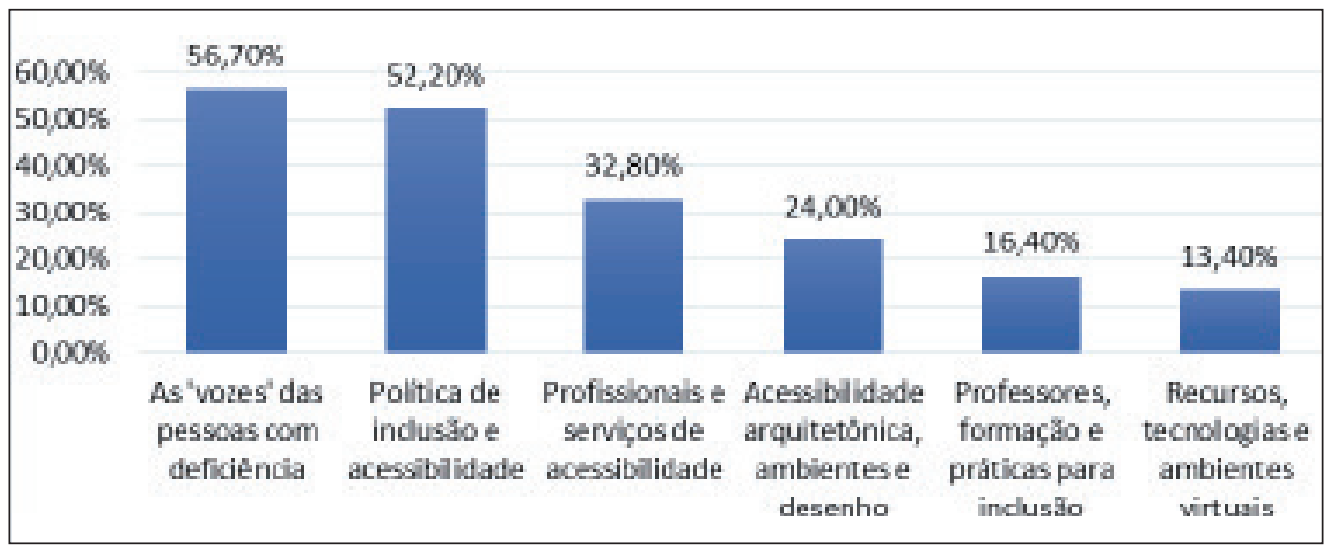

Gráfico 1 - Eixos temáticos trabalhados nas investigaçôes revisadas. Fonte: elaboração Própria. 
Essa divisão dos temas considerou que uma mesma pesquisa pode incluir um ou mais eixos temáticos. As 'vozes' das pessoas com deficiência sobre sua experiência na educação superior foi o tema mais explorado pelos investigadores, totalizando 56,7\% dos trabalhos revisados. Já $52,2 \%$ das pesquisas (segundo eixo temático mais investigado) realizaram estudo documental de leis, políticas, diretrizes institucionais, atlas, relatórios e informes técnicos que trazem dados sobre acessibilidade na universidade. $\mathrm{O}$ terceiro eixo temático mais analisados pelos pesquisadores $(32,8 \%)$ foi o da acessibilidade dos serviços institucionais e profissionais, por exemplo, a atuação do intérprete de Libras, de psicólogos e de assistentes sociais. 24\% das pesquisas trazem dados sobre as condiçóes físicas e estruturais da acessibilidade como nos desenhos, entornos e organização de mobiliários. As práticas pedagógicas, a formação e a expectativa dos professores universitários sobre a inclusão dos estudantes com deficiência foram abordadas por $16,4 \%$ dos pesquisadores. Por último, o eixo temático mais explorado (13,4\%) analisou a acessibilidade a partir do uso de tecnologias e ambientes virtuais de aprendizagem.

Algumas pesquisas apresentaram temas esporádicos, por exemplo, a análise do papel da família na permanência de estudantes com deficiência na universidade (LACERDA, 2013; ALENCAR, 2013); o exame da predisposição dos colegas sem deficiência na convivência de estudantes com deficiência na formação superior (LÓPEZ; ROMERO; FERRER, 2014) e a reflexão sobre a insipiente presença de estudantes com deficiência nos cursos de mestrado e doutorado (SOUZA, 2014; BRANCO, 2015).

Os resultados das pesquisas indicam que desde o ingresso até a formatura os estudantes com deficiência enfrentam diversos tipos de barreiras seja em cursos presenciais ou virtuais (SERRA JUNIOR, 2014; CIANTELLI, 2015; TAVARES, 2014; BRANCO, 2015; SANTOS; 2014). Investigadores mostram que os estudantes com deficiência não conseguem avançar no curso porque desistem das disciplinas pela falta de acessibilidade ou porque são reprovados em razão da deficiência (SILVA, 2014; MOOLA, 2015; SOUZA, 2014). O direito à acessibilidade ainda é de desconhecimento dos estudantes com deficiência como também de boa parte dos membros que compóem a comunidade universitária, por isso a violação desse direito, muitas vezes, se torna imperceptível (CORRÊA, 2014, SILVA, 2014). As políticas afirmativas e os serviços institucionais de acessibilidade não são universalizados e a existência de tais açóes depende de cada universidade (MOOLA, 2015; SILVA, 2014). Muitos universitários com deficiência alegam que as barreiras atitudinais são as que mais dificultam a permanência no curso (RUIZ, 2014; CIANTELLI, 2015; TAVARES, 2014; BRANCO, 2015; SANTOS; 2014; SILVA, 2014). Alguns desses estudantes afirmam não se reconhecer como parte dos grupos de universitários, se sentir invisíveis e com baixo valor intelectual perante os demais colegas (BAU, 2015; SANTOS, 2014).

Em contrapartida, nos textos revisados também aparecem dados positivos sobre a experiência de pessoas com deficiência na educação superior. Corrêa (2014) identificou que os estudantes com deficiência são convidados para bancas de avaliação das condiçóes de acessibilidade na universidade-campo e que existe a atitude institucional que coloca em prática a ideia de protagonismo e o direito de participação social das pessoas com deficiência (ONU, 2006). Lorenzi (2014) constatou que a instituição campo da sua pesquisa busca planejar as condições de acessibilidade com base nos históricos de inacessibilidades apontados pelos estudantes com deficiência. Na mesma linha, Santana (2013), Silva (2014) e Bau (2015) identificaram que 
atitudes inclusivas do professorado, colegas e profissionais contribuem para a permanência de universitários com deficiência. Nas pesquisas, muitos docentes revelaram que o diálogo sistemático com os estudantes com deficiência tem contribuído para orientar sua prática pedagógica (MATOS, 2015, SOUZA, 2014). O uso das tecnologias (seja como apoio assistivo, como ambiente/recurso virtual ou como ferramenta didática) vem sendo um instrumento indispensável para a acessibilidade na participação e aprendizagem dos estudantes com deficiência na universidade (LÓPEZ; ROMERO; FERRER, 2014).

Com base no panorama apresentado nas 72 pesquisas, a seção a seguir traz a discussão sobre as palavras mais frequentes e sobre os termos ausentes, mas que têm relevância para esta investigação.

\subsection{Palavras mais frequentes}

Com o uso do programa NVivo 11 foi gerado uma tabela em Excel com as palavras mais frequentes nos 72 textos selecionados. Dessas palavras, identificamos os 100 termos que mais apareceram, excluindo as preposiçóes e as palavras que náo tem sentido quando analisadas isoladamente (por exemplo, essencial, também, de, com). Nesta fase de garimpagem, agrupamos as palavras em três categorias: (1) contexto macro: os termos que remetem a sistemas globais e amplos, como direito, cultura y educação; (2) contexto institucional: as palavras que se relacionam com o universo acadêmico, por exemplo, formação, oportunidade e currículo e (3) contexto da deficiência: os termos vinculados às experiências das pessoas com deficiência, como diversidade, integração e autoadvocacia.

Na primeira categoria, oito palavras foram mais utilizadas pelos pesquisadores:

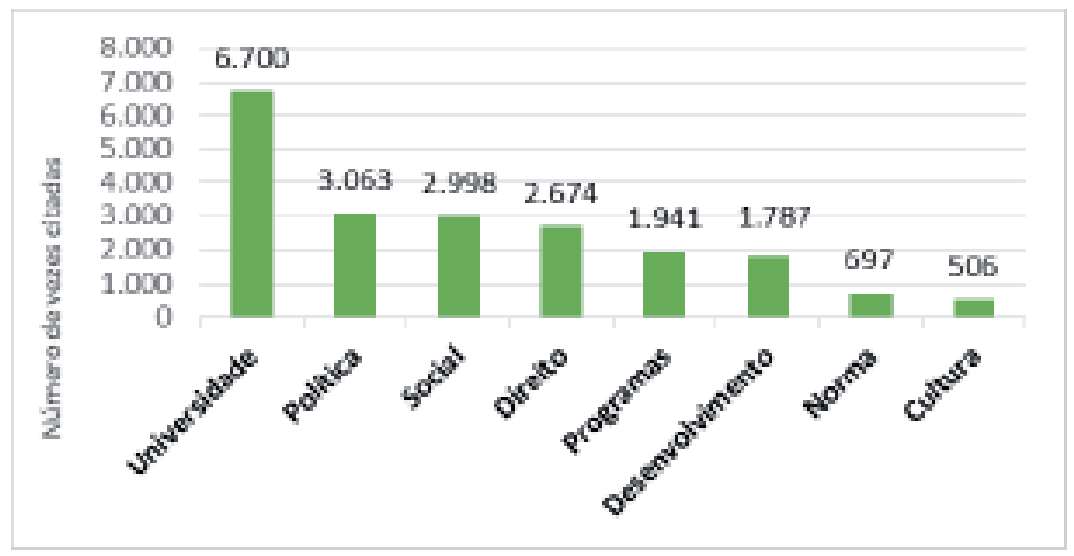

Gráfico 2 - As palavras mais frequentes no contexto macro da revisão.

Fonte: elaboração própria.

Em razão da escolha das palavras-chave delimitadas na etapa inicial da revisão de literatura, consequentemente, as palavras mais citadas pelo NVivo 11 foram 'universidade', 'acessibilidade' e 'deficiência'. Quase todas as investigaçóes contextualizaram a acessibilidade nas políticas e no marco legal do seu país, reconhecendo o direito inerente da pessoa com deficiência de ir, vir 
e se comunicar nas instituiçóes de educação superior. Desta forma, referente à acessibilidade nas instituições de educação superior, a legislação e a política são temas frequentemente explorados pelos pesquisadores e, por isso, os autores apresentam em seus resultados diversos casos de violação deste direito nas experiências de estudantes, professores e funcionários com deficiência.

'Cultura', 'desenvolvimento' e 'normas' também foram palavras sistematicamente mencionadas pelos pesquisadores, como mostra o gráfico 1. Essas palavras remetem tanto aos aspectos materiais como à dimensão simbólica da acessibilidade. Ao mesmo tempo, os três termos ampliam a discussão sobre acessibilidade porque adentram em elementos não-materiais para reflexionar sobre a construção humana ao que parece meramente arquitetônico e impessoal no ambiente comum. A palavra 'desenvolvimento' aparece nos textos como 'efeito de desenvolver algo' programa, projeto, meta ou ação. Um segundo sentido para esta palavra é o desenvolvimento individual como a possibilidade de participação, aprendizagem ou avanço na formação acadêmica. $\mathrm{O}$ aparecimento da palavra 'desenvolvimento' nas pesquisas sobre acessibilidade aproxima, ainda que de forma não intencional ou direta, os conceitos de acessibilidade e desenvolvimento humano, este último fundamentado na discussão sobre os indicadores da Organização das Nações Unidas que introduzem normas para a "ampliação das opções de vida" (PNUD, 2016, p. 1), condição que também está prevista nas diretrizes para acessibilidade (ONU, 2006).

No contexto institucional da educação superior, 31 palavras apareceram com destaque. O gráfico 3 apresenta quais foram as palavras e o número de sua frequência:

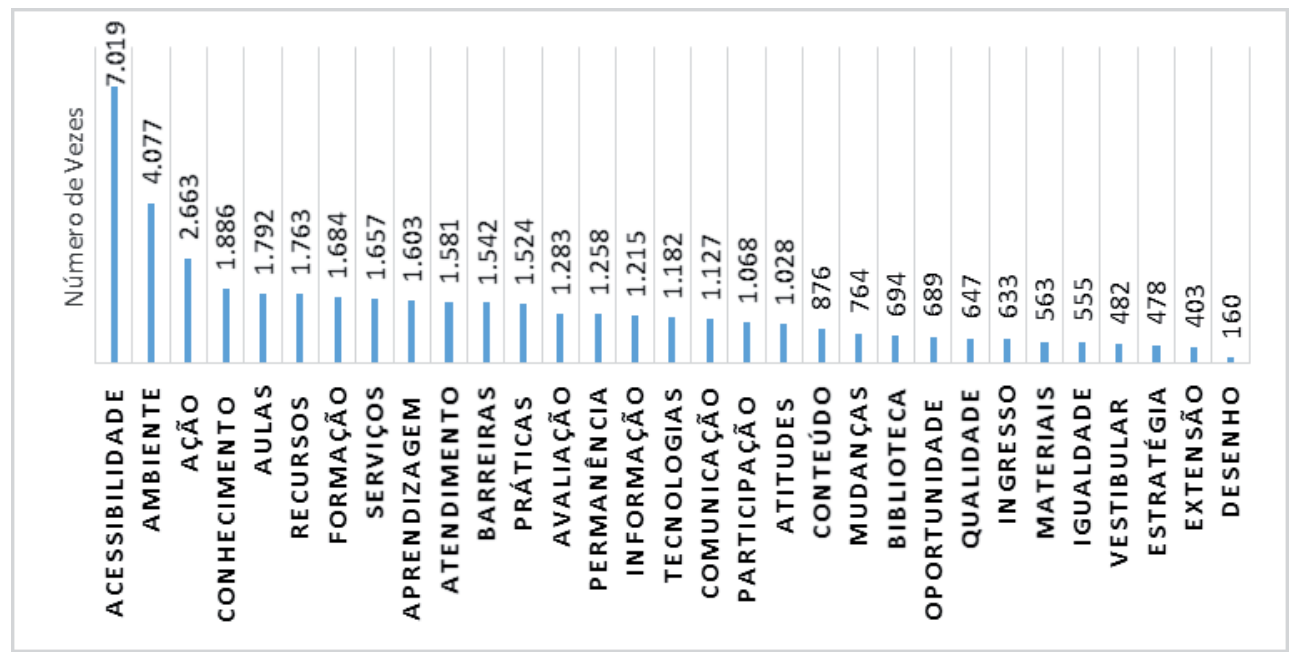

Gráfico 3 - As palavras mais frequentes no contexto institucional.

Fonte: elaboração própria.

Eliminando a palavra 'acessibilidade', por ser uma das palavras-chave, os três termos que emergiram com mais frequência foram 'ambiente', 'ação' e 'conhecimento'. Neste contexto, quando se abordam as questóes de acessibilidade na educação superior, os espaços físicos são os primeiros mencionados. É provável que isso seja em razão da própria origem da palavra acessibilidade que tem sua gênese nas modificaçóes estruturais (SASSAKI, 2004). Por isso, esse 
conceito foi desenvolvido com predomínio nas ciências exatas como Arquitetura, Engenharia e Tecnologias (LIPPO, 2012). Em seguida, a palavra 'ação' foi a segunda mais citadas no contexto institucional e está articulada aos 'serviços' $\left(8^{\circ 7}\right)$ e as 'atitudes' $\left(19^{\circ}\right)$. Portanto, há preocupação dos pesquisadores com as relaçóes psicossociais que estão presentes na oferta de serviços e nas atitudes da comunidade universitária com relação às pessoas com deficiência.

Seguindo a ordem do gráfico, a palavra 'conhecimento' foi a terceira que apareceu nas buscas e pode ser associada às 'aulas' $\left(4^{\circ}\right)$, aos 'conteúdos' $\left(20^{\circ}\right)$ e ao processo de produção da pesquisa. A 'aprendizagem' $\left(8^{\circ}\right)$ do currículo na 'formação' $\left(6^{\circ}\right)$ acadêmica foi enfatizada pelos autores como um desafio por causa de diferentes 'barreiras' $\left(11^{\circ}\right)$ de ingresso e permanência das pessoas com deficiência na universidade. Por consequência, os investigadores utilizaram sistematicamente os termos 'oportunidade' $\left(23^{\circ}\right)$ e 'igualdade' $\left(27^{\circ}\right)$ de 'participação' $\left(18^{\circ}\right)$, bem como a 'qualidade' $\left(24^{\circ}\right)$ e 'práticas' $\left(12^{\circ}\right)$ de estratégias $\left(29^{\circ}\right)$ didáticas e de avaliação $\left(13^{\circ}\right)$ para avaliar a experiência de estudantes com deficiência em cursos superiores.

O acesso à 'informação' $\left(15^{\circ}\right)$ e à 'comunicação' $\left(17^{\circ}\right)$ também apareceram com sistemática nas 72 investigaçóes, reforçando a multidimensionalidade da acessibilidade na educação superior e o direito humano da livre expressão e conhecimento (ONU, 1948). Já a tecnologia foi a $16^{\circ}$ palavra mais citada e aparece com o sentido de apoio assistido, de recurso didático ou vinculada ao contexto da educação à distância. Mesmo os investigadores que analisaram a educação superior presencial demonstraram preocupação com o impacto das novas tecnologias na formação acadêmica de estudantes com deficiência, sobretudo, focalizando o acesso à informação institucional acessível.

No terceiro e último contexto, o da deficiência, 19 palavras foram identificadas. O gráfico 4 indica as palavras emergentes e a quantidade de vezes em que elas aparecem:

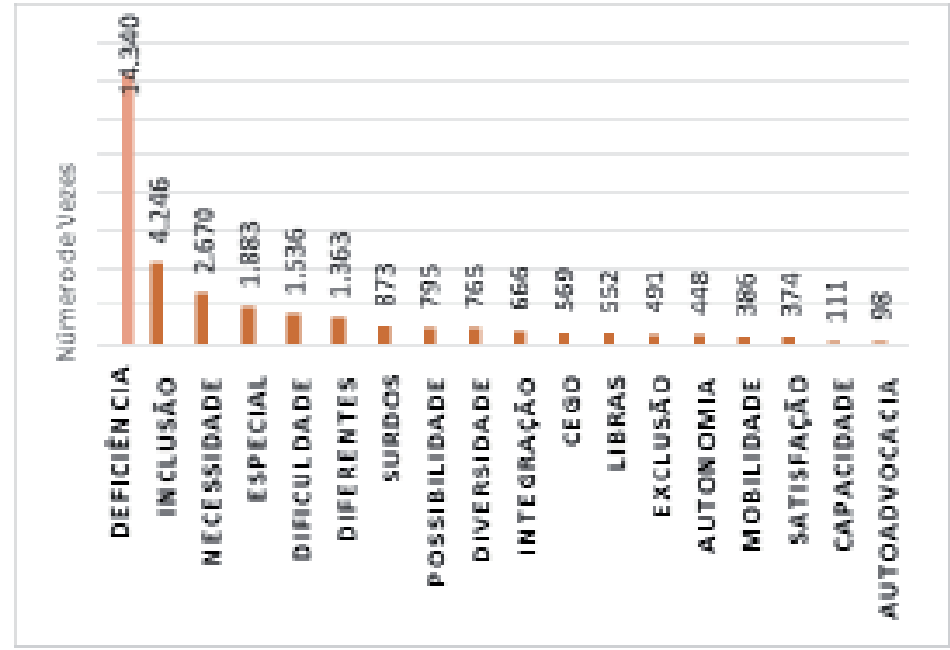

Gráfico 4 - As palavras mais frequentes no contexto da deficiência. Fonte: elaboração própria.

${ }_{7}^{7}$ Ordem em que a palavra aparece no gráfico. 
Por tradição a palavra deficiência faz alusão ao termo 'especial', quarta palavra mais citada nas pesquisas. Este termo denomina tanto uma subárea de conhecimento da Educação (Educação Especial) como um campo de atuação profissional, além de caracterizar um coletivo particular: o das pessoas com deficiência ou dos alunos com necessidades especiais (GLAT, 2004). Com o intenso e atualizado debate sobre o modelo social da deficiência (OLIVER, 1983; FERREIRA, 2004; GIL, 2011; CARVAJAL, 2015), o termo 'especial' passou a ser contestado por sua proximidade com os pressupostos que sustentam a ideia de normalidade (WOODWARD, 2000). Do mesmo modo, os termos 'necessidade' ( $\left.3^{\circ}\right)$ e 'dificuldade' $\left(5^{\circ}\right)$ tiveram grande visibilidade nos trabalhos revisados. Ambas as palavras trazem resquício daquilo que falta, da suposta carência, ausência ou defeito da deficiência. Esta tendência investigativa acaba, sutilmente, personificando a tragédia da deficiência (OLIVER, 1983) que transfere para o indivíduo a fatalidade da sua condição físico-cognitiva e, ao mesmo tempo, sustenta e reproduz uma norma ideal (SKLIAR; SOUZA, s/d).

No jogo interpretativo, a palavra 'inclusão' $\left(2^{\circ}\right)$ é citada pelos autores como oposição à 'exclusão' (13º seja no contexto de políticas, leis, e serviços institucionais como também por meio de práticas pedagógicas, atitudes, ações e relaçóes. Segundo Lopes (2004), inclusão e exclusão são resultados de uma mesma construção cultural, pedagógica e ideológica. A autora complementa que

Todo espaço determinado por uma determinada ordem é delimitado e governado por uma norma. Esta norma classifica, compara, avalia, inclui e exclui. Toda lei mantém aqueles denominados excluídos fora de seu controle, pois não cabe pensar no excluído, mas sim prever o incluído (LOPES, 2004, p. 11).

Neste contexto, a norma que legitima os que estão incluídos é a mesma que cria a fronteira que produz o grupo excluído. Seguindo essa lógica, o diálogo sobre acessibilidade deve, necessariamente, valer-se da linha tênue que comporta inclusão e exclusão para avançar no debate e aproximar-se dos processos imbricados nos funcionamentos das normas institucionais que são as reais produtoras de barreiras contra os estudantes com deficiência.

Pode dizer que, ao mesmo tempo que inclusão existe para exclusão, 'capacidade' $\left(17^{\circ}\right)$ compreende a 'deficiência' $\left(1^{\circ}\right)$. A análise contextualizada dos termos nos trabalhos mapeados mostra que a palavra 'deficiência' é qualificada isoladamente, sem a vinculação aos critérios que somam o significado da capacidade intelectual acadêmica. Quando a capacidade é argumentada pelos autores é reivindicada como uma característica essencialista e inata às pessoas com deficiência (por exemplo, quando se diz que 'os estudantes com deficiência são também capazes'). No entanto, além de pensar sobre a deficiência em si, é possível realizar o movimento contrário: $\mathrm{O}$ que significa a capacidade? O que representa ser capaz na universidade? Quais critérios são associados aqueles ditos pessoas sem deficiência frente às pessoas rotuladas como deficientes?

A 'diversidade' $\left(9^{\circ}\right)$ e a 'diferença' $\left(6^{\circ}\right)$ também tiveram grande visibilidade nos trabalhos e são celebradas nos debates contemporâneos sobre educação inclusiva (WOODWARD, 2000; FERREIRA, 2004). Esses conceitos, ainda que abordados no mesmo contexto de análise, no entanto, são discursos com sentido político singular. Enquanto o discurso sobre diversidade insinua o reconhecimento da intrínseca pluralidade humana, ressaltando as variedades de aspectos fisiológicos e estéticos, a conceituação sobre diferenças destrona os parâmetros de ser 
humano a partir do pressuposto de que é necessário desnaturalizar qualquer característica dita como biológica e essencialista, pois qualquer diferença humana como sexo, cor ou deficiência em si não é uma característica inata ou natural dos indivíduos, mas tais diferenças ganham sentido e representação nas relações culturais e nos contextos intersubjetivos (GANGUILHEM apud SKLIAR; SOUZA, s/d).

Ainda sobre este ponto, nesta revisão de literatura, muitas vezes, o uso do termo 'diversidade' reforça o sentido 'natural' da pluralidade que pode ser comparado com o processo de afirmação da nossa essência humana frente ao racismo - a velha confirmação de que somos todos humanos ou a ênfase na construção de uma consciência humana em detrimento das pautas específicas de reivindicação de grupos raciais. O discurso de diversidade se converte em "[...] uma variável aceitável e respeitável no projeto hegemônico de normalidade [...]" que mantém os sistemas de representação, as fronteiras e as desigualdades e ainda "[...] obscurece o significado político das diferenças culturais [...]" em favor de "[...] um certo pluralismo que se refere sempre a uma norma ideal”. (SKLIAR; SOUZA, s/d, p. 6-7). Justamente para não correr este risco discursivo de naturalização e despolitização das diferenças e identidades, é necessário um trabalho cognoscitivo nas pesquisas, de desconstrução-construção das marcas de identidade e dos sujeitos marcados como diferentes e não-diferentes para identificar as normas culturais que desqualificam/qualificam e subordina/domina um grupo ou pessoa frente a outro (SANTOS, 1997), levando aqui em consideração a dinâmica e os acordos do contexto específico da educação superior.

Por outro lado, nas investigações revisadas, as palavras 'possibilidades' $\left(8^{\circ}\right)$ de atuação das pessoas com deficiência de expressarem sua satisfação $\left(16^{\circ}\right)$ e o nível de autoadvocacia $\left(18^{\circ}\right)$ foram temas de interesse dos investigadores. Assim, se tratando da educação superior, a autoadvocacia é uma temática presente no contexto da investigação. Articuladamente, os temas da autonomia $\left(14^{\circ}\right)$ e mobilidade $\left(14^{\circ}\right)$ também tiveram grande destaque nos resultados das frequências de palavras e trouxeram indícios de que a acessibilidade não é uma técnica universal, isto é, depende da experiência particular e da avaliação de cada pessoa com deficiência em interação com o ambiente, com os recursos e com as pessoas (LIMEIRA, 2014).

As palavras mais citadas pelos investigadores têm relevância na revisão de literatura porque indicam as problemáticas emergentes frente a um objeto de estudo e mostram os principais termos que são mais trabalhados em determinada temática. Da mesma forma, os conceitos que são importantes para um projeto de pesquisa, mas que são poucos mencionados ou não aparecem na revisáo de literatura revelam a relevância de se explorar este novo enfoque em um trabalho investigativo.

\subsection{Palavras ausentes}

Chama a atenção que tratando-se de acessibilidade e educação superior, os buscadores de frequência de palavras não identificaram nos 72 trabalhos os termos 'feminismo' e 'gênero'. A palavra 'mulher', nas reduzidas vezes que aparece, está relacionada ao sexo das participantes e aos trechos da ONU que abordam pautas sobre inclusão e diversidade. Esse dado revela que é necessário a introdução das questôes de feminismo e gênero na análise sobre acessibilidade na educação superior porque a ausência do tratamento científico representa uma brecha que invisibiliza as desigualdades e as restriçóes geradas pelas relaçóes de gênero que colocam em 
condição de vulnerabilidade múltipla e desvantagem as mulheres com deficiência (DANTAS; SILVA; CARVALHO, 2014) que estão ou querem ingressar à educação superior.

\section{Conclusốes}

Esta revisão de literatura conduz uma investigação de doutorado que busca analisar as condiçốes de acessibilidade para mulheres com deficiência que estão na educação superior. O panorama dos trabalhos científicos mapeados mostra dados produzidos por pesquisadores de diferentes países. $\mathrm{O}$ acesso à informação variada contribui para o processo de hibridização do conhecimento, assim como, amplia as reflexôes sobre o sentido e a dinâmica da acessibilidade na experiência universitária de pessoas com deficiência de diferentes localidades. Os principais resultados dessa revisão indicam que os pesquisadores analisaram o tema da acessibilidade por diferentes enfoques; supóe-se que em razão do caráter interdisciplinar deste conceito. A multidimensionalidade do sentido da acessibilidade faz com que os pesquisadores busquem respostas em outros campos científicos e com isso saiam dos limites da hiperespecialização do campo da Educação Especial.

Dentre os achados identifica-se que os estudos são em maioria qualitativos - salvo os casos de alguns pesquisadores que mesclaram métodos qualitativos com técnicas de quantificação -, exploratórios e partem de 'hipóteses negativas', considerando dificuldades, fracasso, necessidades e barreiras encontradas pelas pessoas com deficiência na trajetória universitária. Justamente por isso, alguns autores trazem recomendaçóes, no capítulo final de seu estudo, como forma de contribuir para a melhoria da acessibilidade. Há uma participação predominante de mulheres que investigam a acessibilidade na educação superior, dado que corrobora com os estudos feministas ao caracterizarem a divisão de gênero nos interesses por disciplinas acadêmicas e objetos de estudo. Neste caso, o estudo sobre a acessibilidade na experiência de pessoas com deficiência está atrelado, na maioria das vezes, às áreas relacionadas ao cuidado e à assistência, ainda que a interdisciplinaridade do conceito induza ao desenvolvimento de estudos em disciplinas de exatas e tecnológicas e por isso chame a atenção de investigadores-homens.

No agrupamento das 72 pesquisas, seis eixos principais tiveram destaque: (1) as 'vozes' das pessoas com deficiência e sua participação direta na produção de dados sobre acessibilidade na educação superior; (2) política de inclusão e acessibilidade; (3) profissionais e serviços de acessibilidade; (4) acessibilidade arquitetônica, ambientes e desenho; (5) professores, formação e práticas pedagógicas para inclusão e (6) recursos, tecnologias e ambientes virtuais. Conjuntamente, a identificação das palavras mais frequentes foi uma fase relevante para a revisão da literatura porque indicou os enfoques que emergiram na discussão dos 88 autores e permitiu a elaboração de um painel conceitual para fundamentação da tese em questão. Do mesmo modo, as palavras ausentes como 'gênero' e 'mulher' validaram a hipótese do projeto de pesquisa quanto à relevância acadêmica de introduzir estes conceitos na análise sobre acessibilidade na educação superior.

Vale destacar que esta revisão de literatura introduz alguns pontos que necessitam ser aprofundados ou, ainda, refutados em estudos posteriores que tenham como foco contabilizar um número maior de publicações. Dessa forma, sugere-se como possíveis temas (a) o estudo representativo sobre o perfil de pesquisadores e pesquisadoras que investigam a deficiência no âmbito da educação superior; (b) o uso de métodos comparativos para análise entre países da 
disposição da acessibilidade para estudantes com deficiência; (c) a pesquisa inter/transdisciplinar para revisar a noção atual de acessibilidade; (d) o mapeamento das barreiras de gênero que provocam desigualdade entre mulheres e homens com deficiência e/ou mulheres e homens sem deficiência nas carreiras universitárias; (e) a análise da influência da condição de deficiência no ingresso à educação superior a partir do entrelace das variáveis renda, juventude, raça/etnia, sexualidade, entre outras e (f) a apreciação conceitual da proximidade entre as definiçóes de acessibilidade e de equidade/igualdade de gênero.

O mundo digital tem contribuído para a intensa disseminação de publicaçôes científicas e, com isso, tem permitindo o acesso aberto, rápido e de baixo custo de acervo intelectual. Agora é desafio dos pesquisadores acompanhar o fluxo dinâmico, veloz e atualizado da disseminação de textos científicos. Para isso, é necessário o desenvolvimento e aperfeiçoamento de métodos e da capacidade crítica para filtrar, relacionar, analisar e aprofundar as informaçóes encontradas nos bancos de dados. Desta forma, a revisão de literatura não deve ser vista como uma etapa secundária da investigação empírica, mas como um momento importante em que o pesquisador observa, critica e autoavalia aquilo que foi delimitado e deduzido no projeto de pesquisa. A revisão de literatura é o momento propício para evitar o risco de se 'reinventar a roda' e de cair na reprodução simplista do conhecimento. É preciso evitar o desperdício de tempo, esforço e recurso em trabalhos que acabam mantendo a circularidade e a repetição do conhecimento, daí a necessidade de inovação e de divulgação de desenhos de revisão de literatura que sejam alternativas para os pesquisadores das diferentes áreas.

\section{REFERÊNCIAS}

ALENCAR. P.M.M. Acessibilidade no ensino superior: O caso da UFJF. 2003. 151f. Dissertação (Mestrado Profissional em Gestão e Avaliação da Educação Pública) - Faculdade de Educação, Universidade Federal de Juiz de Fora, Juiz de Fora, 2013.

BAU, M.A. Avaliação da acessibilidade no ensino superior: UTFPR Campus Medianeira. 2015. 123f. Dissertação (Mestrado em Educação) - Faculdade de Filosofia e Ciências, Universidade Estadual Paulista, São Paulo, 2015.

BORGES, J.A.S. Sustentabilidade e acessibilidade no ensino superior: contribuiçóes para um diagnóstico socioambiental da PUCRS. 2013. 144f. Dissertação (Mestrado em Educação) - Faculdade de Educaçáo, Pontifícia Universidade Católica do Rio Grande do Sul, Porto Alegre, 2013.

BRANCO, A.P.S.C. Análise das condiçôes de acessibilidade no ensino superior: um estudo com pós-graduandos Bauru. 2015. 164f. Dissertação (Mestrado em Psicologia do Desenvolvimento e Aprendizagem) - Faculdade de Ciências, Universidade Estadual de São Paulo, São Paulo, 2015.

BRAVO, R.S. Tesis doctoral y trabajo de investigación cientifica: Metodología general de su elaboración y documentación. Madrid: Editorial Paraninfo, 1996.

BRASIL. INEP. Relatório Técnico do Censo da Educação Superior. 2015. Disponível em: <http:// portal.inep.gov.br/web/guest/censo-da-educacao-superior >. Acesso em: 19 maio 2017.

BRUNELLI. N.G. Estudantes com deficiência no ensino superior: acesso e permanência numa instituição pública de ensino. 2015, 138f. Dissertação (Mestrado em Educação) - Faculdade de Educação, Universidade Federal da Bahia, Salvador, 2015.

BURIN, M. Las "Fronteras de cristal” en la carrera laboral de las mujeres. Género, subjetividad y globalización. Anuario de Psicología, Barcelona, v.39, n.1, p.75-86, 2008. 
CARUSO, M. TENORTH. H. Introducción: conceptuar e historizar la internacionalización y globalización en el campo educativo. In. CARUSO, M. TENORTH. H. (Org.). Internacionalización: Política educativas y reflexión pedagógica en medio global. Buenos Aires: Ed. Germánica S.A, 2011. p. 19-42.

CARVAJAL, M. Política de discapacidad e inclusión de la Universidad del Valle: un proceso participativo. Sociedad y economía, Colombia, v.29, n.1, p.175-201, 2015.

CIANTELLI, A.P.C. Estudantes com deficiência na universidade: contribuiçóes da psicologia para as ações do núcleo de acessibilidade. 2015. 186f. Dissertação (Mestrado em Psicologia do Desenvolvimento e Aprendizagem) - Faculdade de Ciências, Universidade Estadual Paulista Júlio De Mesquita Filho, Bauru, 2015.

CORRÊA, P.M. Acessibilidade no ensino superior: instrumento para avaliação, satisfação dos alunos com deficiência e percepção de coordenadores de cursos. 2014. 281f. Tese (Doutorado em Educaçáo) Faculdade de Filosofia e Ciências, Universidade Estadual Paulistana, Marília, 2014.

CRUZ, M.H.S. Mapeando diferenças de gênero no ensino superior da Universidade Federal de Sergipe. São Cristóvão: Editora UFS, 2012.

DANTAS, T.C. SILVA, J.S. CARVALHO, M.E. Entrelace entre gênero, sexualidade e deficiência: uma história feminina de ruptura e empoderamento. Revista Brasileira de Educação Especial, Marília, v.20, n.4, p.555-568, 2014.

FERREIRA, W.B. Invisibilidade, crenças e rótulos: Reflexão sobre a profecia do fracasso educacional na vida de jovens com deficiência. In: IV CONGRESSO BRASILEIRO SOBRE SÍNDROME DE DOWN. 4., 2004, Recife. Anais eletrônicos... Bahia: Associação de Pais e Amigos dos Excepcionais, 2004.

FUENTES, S.S. VILLORIA, E.D. ALMARAZ, R.A.M. El diseño universal como medio para atender a la diversidad en la educación. Una revisión de casos de éxitos en la universidad. Contexto Ed, Logrońo, v.19, n.1, p.121-131, 2016.

GIL, F.G. Inclusión y atención al alumnado con necesidades educativas especiales en España. 2011. Disponível em: <www.mecd.gob.es/revista-cee/pdf/n18-gonzalez-gil.pdf >. Acesso em 21 jul. 2017.

GLAT, R. Autodefensoria/Auto-gestão: Movimento em prol da autonomia de pessoas com deficiência mental - uma proposta político-educacional. In: CONGRESSO ESTADUAL DAS APAEs DE MINAS GERAIS, 3, 2006, Minas Gerais. Anais eletrônicos... Belo Horizonte, 2004.

SERRA JUNIOR, L.R. Luz do conhecimento na escuridão do olhar: acessibilidade aos estudantes de ensino superior com deficiência visual no ensino à distância. 2014. 128f. Dissertação (Mestrado Profissional em Políticas Públicas e Gestão da Educação Superior) - POLEDUC, Universidade Federal do Ceará, Fortaleza, 2014.

JUVENCIO, V.L.P. Contribuição das tecnologias da informação e comunicação (Tics) para a acessibilidade de pessoas com deficiência visual: O caso da universidade Federal do Ceará. 2013. 156f. Dissertação (Mestrado Profissional em Políticas Públicas e Gestão da Educação Superior) - POLEDUC, Universidade Federal do Ceará, Fortaleza, 2013.

LACERDA, G.B. Políticas de acesso, autonomia e permanência da pessoa com deficiência nas instituiçôes públicas de ensino superior da regiâo metropolitana do Cariri. 2013. 141f. Dissertação (Mestrado profissional em Políticas Públicas e Gestão da Educação Superior) - POLEDUC, Universidade Federal do Ceará, Fortaleza, 2013.

LIMEIRA. C.S. Acessibilidade física e inclusão no ensino superior: Um estudo de caso na Universidade Federal do Pará. 2014. 131f. Dissertação (Mestrado em Educação) - Instituto de Ciências da Educação, Universidade Federal do Pará, Belém, 2014. 
LIPPO, H. Sociologia da acessibilidade e reconhecimento politico das diferenças. 1 ed. Canoas: Ed. ULBRA, 2012.

LÓPEZ, P.S. ROMERO, M.P.A. FERRER, M.S. Opinión de docentes y estudiantes acerca del uso de las TIC como herramienta para la inclusión de una estudiante con discapacidad. Revista Interuniversitaria de Formación del Profesorado, Zaragoza, v.28, n.1, p.67-82, 2014.

LOPES, M.C. A inclusão como ficção moderna. Pedagogia: a revista do curso, São Miguel do Oeste, v.6, n.1, p.7-20, 2004.

LORENSI, V.M. A Inclusão Educacional e Educação Superior: Realidade e Perspectivas na Educação a Distância. 2014. 212f. Dissertação (Mestrado em Educação) - Centro de Educação, Universidade Federal de Santa Maria, Santa Maria, 2014.

MATOS, A.P.S. Práticas pedagógicas para inclusão de estudantes com deficiência na educação superior: um estudo na UFRB. 2015. 196f. Dissertação (Mestrado em Educação) - Faculdade de Educação, Universidade Federal da Bahia, Salvador, 2015.

MOOLA, J.F. The Road to the Ivory Tower: The Learning Experiences of Students with Disabilities at the University of Manitoba. Qualitative Research in Education, Manitoba, v.4, n.1, p.45-70, 2015.

MORIN, E. Sobre la interdisciplinaridad. 2010. Disponível em: <http://www.javeriana.edu.co/ archivo/ahj2012/paginas/m_ins/doc_ins/o_uni/ORIENTACIONES/PDF_ORIENTACIONES/43. pdf >. Acesso em: 17 jun. 2017.

OLIVER, M. Social work with disabled people. London: MacMillan. 1983. Disponível em: < http:// www.icjp.pt/sites/default/files/media/723-1116.pdf >. Acesso em: 20 out. 2013.

ONU. Declaração Universal dos Direitos Humanos. 1948. Disponível em: <http://www.mj.gov.br/sedh/ ct/legis_intern/ddh_bib_inter_universal.htm >. Acesso em: 28 abr. 2017.

ONU. Convenção sobre os Direitos das Pessoas com Deficiência. 2006. Disponível em: <http://www.inr. pt/uploads/docs/direitosfundamentais/convencao/ConvTxtOfPort.pdf >. Acesso em: 21 jun. 2017.

PÉREZ, P.R.A. AGUILAR, D.L. Atención del profesorado universitario a estudiantes con necesidades educativas específicas. Educ. Educ., Cundinamarca, v.2, n.18, p.193-208, 2015.

PINTO, E.J.S. CARVALHO, M.E.P. RABAY, G. As relações de gênero na escolha de cursos superiores. Revista Tempos e Espaços em Educação, São Cristóvão, v.10, n.22, p.47-58, 2017.

PNUD. Relatório do Desenvolvimento Humano. 2016. Disponível em: <http://hdr.undp.org/en/2016report $>$. Acesso em 18 mai. de 2017.

RICARDO, A.C. ANGARITA, M.M. Educación superior y discapacidad: Análisis desde la Experiencia de algunas Universidades Colombianas, Revista Española de Discapacidad, Madrid, v.2, n.2, p.83-101, 2014.

RIO, A.Z. PASTOR, C.A. La discapacidad en la percepción de la tecnología entre estudiantes universitarios. Comunicar, Madrid, v.20, n.40, p.165-172, 2013.

RUIZ, A.L. ¿Educación inclusiva? Análisis del marco jurídico sobre el derecho de acceso y permanencia en la educación superior para las personas Sordas en la ciudad de Bogotá. Revista de Derecho Público, Bogotá, n.33, p.1-55, 2014.

SALLÁN, J.G. MORENO, J.L.M. La acción tutorial en los estudiantes universitarios con discapacidad. Educación, Madrid, v.23, n.43, p.71-90, 2013. 
SANTANA, E.S. Atitudes de estudantes universitários frente aos alunos com deficiência na UNESP de Presidente Prudente. 2013. 188f. Tese (Doutorado em Educação) - Faculdade de Filosofia e Ciências, Universidade Estadual Paulista, Marília, 2013.

SANTOS, F.C. As Disciplinas de exatas e o processo de ensino para alunos com deficiência visual na Universidade Federal de Sergipe. 2014. 128f. (Mestrado em Ensino de Matemática) - Departamento de Ensino de Matemática, Universidade Federal do Sergipe, São Cristóvão, 2014.

SANTOS. B.S. Por uma concepção multicultural de direitos humanos. 1997. Disponível em: <http:// www.boaventuradesousasantos.pt/media/pdfs/Concepcao_multicultural_direitos_humanos_RCCS48. PDF >. Acesso em 20 jan. 2013.

SASSAKI, R.K. Acessibilidade: Uma chave para a inclusão social. 2004. Disponível em: <http://www. lainsignia.org/2004/junio/soc_003.htm >. Acesso em 05 mai. 2013.

SILVA, J.S.S. Acessibilidade, barreira e superação: Estudo de caso de experiências de estudantes com deficiência. 2014. 242f. Dissertação (Mestrado em Educação) - Centro de Educação, Universidade Federal da Paraíba, Joáo Pessoa, 2014.

SILVA, J.S.S. FERREIRA, W.B. Do Encapsulamento da Educação Especial à Interdisciplinaridade dos Estudos Culturais: Revisão das Noções de Deficiência na Produção Científica Brasileira. In: 4to CONGRESO LATINOAMERICANO Y CARIBEÑO DE CIENCIAS SOCIALES DA USAL/ FLACSO, 7, 2017, Anais impressos... Salamanca, 2017.

SKLIAR. C. SOUZA, R.M. Consideraçôes sobre as diferenças: caminhos para se (re)pensar a educação. s/d. Disponível em: <http://www.lite.fe.unicamp.br/cursos/nt/ta2.1.htm>. Acesso em 23 jan. 2017.

SOUZA. T.F.B. Políticas públicas para a pessoa com deficiência na UFC: a percepção dos alunos com deficiência visual. 2014. 147f. Dissertação (Mestrado em Políticas Públicas e Gestão da Educação Superior) - POLEDUC, Universidade Federal do Ceará, Fortaleza, 2014.

STROPARO, E.M. Politicas Inclusivas e Acessibilidade em Bibliotecas Universitárias: uma Análise do Sistema de Bibliotecas da Universidade Federal Do Paraná. 2014. 263f. Dissertação. (Mestrado em Educação) - Centro de Educação, Universidade Federal do Paraná, Curitiba, 2014.

TAVARES, A.P.P. Educação especial no ensino superior: acessibilidade no processo de inclusão escolar, a partir de relatos de acadêmicos com deficiência. 2014. 141f. Dissertação (Mestrado em Psicologia) Departamento de Psicologia, Universidade Estadual de Maringá, Maringá, 2014.

VIEJO, C. M. MARTÍNEZ, A. I. Barreras arquitectónicas, mentales y de comunicación: mujeres con diversidad funcional. La manzana de la discordia, Cali, v.11, n.1, p.55-71, 2016.

VIGENTIM, U.D. Tecnologia Assistiva: analisando espaços de acessibilidade às pessoas com deficiência visual em universidades públicas. 2014. 125f. Dissertação (Mestrado em Educação Escolar) - Faculdade de Ciências e Letras, Universidade Estadual Paulista Júlio de Mesquita Filho, Araraquara, 2014.

VILLA, C.F; ALLER, M.J.V; GARCÍA, J.V. La atención a los estudiantes con discapacidad en las instituciones de educación superior. El caso de Cataluña. Revista de investigación Educativa, Cataluña, v.32, n.1, p.139-157, 2014.

WOODWARD, K. Identidade e diferença: uma introdução teórica e conceitual. In: SILVA, T. T. (Org.). Identidade e diferença: a perspectiva dos estudos culturais. Petrópolis: Vozes, 2000. p.33-58.

Recebido em: 10/06/2017

Reformulado em: 06/12/2017

Aprovado em: 10/12/2017 